\title{
Large Peripheral Osteoma of the Mandible: A Case Report
}

\author{
Aydin OZKAN ${ }^{1, *}$, Can Engin DURMAZ ${ }^{2}$, Armagan GUNAL ${ }^{3}$ \\ ${ }^{1}$ Gulhane Military Medical Academy and Turkish Land Forces Infirmary, Oral and Maxillofacial Surgery, Ankara, Turkey \\ ${ }^{2}$ Cankaya Oral and Dental Health Clinics, Oral and Maxillofacial Surgery, Ankara, Turkey \\ ${ }^{3}$ Gulhane Military Medical Academy, Department of Pathology, Anakara, Turkey \\ *Corresponding author: yndozkan@yahoo.com
}

Received May 22, 2015; Revised May 29, 2015; Accepted May 31, 2015

\begin{abstract}
Osteoma is a benign, slow-growing osteogenic lesion that sometimes arises from the maxillofacial region, such as the sinus, temporal or jaw bones. Osteoma of the mandible is a rare entity with very few cases reported in the literature. This paper reports an additional case of osteoma in the mandible in a 21-year-old male patient. The purpose of this paper is to present clinical, radiographic, surgical and histopathological features of an osteoma of the mandible and treatment of this lesion.
\end{abstract}

Keywords: osteoma, mandible, pathology

Cite This Article: Aydin OZKAN, Can Engin DURMAZ, and Armagan GUNAL, "Large Peripheral Osteoma of the Mandible: A Case Report.” International Journal of Dental Sciences and Research, vol. 3, no. 3 (2015): 79-81. doi: 10.12691/ijdsr-3-3-8.

\section{Introduction}

Although osteoma is a benign tumor which is generally seen in long bones, it can be also seen in maxillofacial region rarely. Region of mandible bone and paranasal sinuses are most affected sites. In general, osteoma is osteogenic lesion with a very slow growth, characterized by proliferation of either cancellous or compact bone. Depending on its location osteoma may be classified as central, periferal, or extraskeletal type [1]. The central osteoma arises from the endosteum, the peripheral osteoma arises from the periosteum and the extra-skeletal soft tissue osteoma usually develops within the muscle. Osteoma is seen in young adults and commonly it gives no symptoms but it can be determined with the facial asymmetry that caused by gradual growing in maxillofacial region. Radiographically, osteoma appear as well-circumscribed radiopaque masses that appear round or ovoid in shape [2]. If the osteoma is peripheral type, the lesion may be sessile or pedunculated to cortical bone. Histologically, osteoma consists of mature, lamellar bone or cancellous bone with abundant fibro-fatty marrow between bony trabeculae. Osteoma is treated by surgical excision. Recurrence of osteoma after surgical excision is extremely rare [3].

This study aimed to present an uncommon case of peripheral osteoma in the mandible and discuss it in relation to cases reported in the literature.

\section{Case Report}

The patient was a 21-year-old male who was admitted to our department with 10 year history of swelling and asymmetry in the right mandibular region. He didn't have a history of trauma or injury to his jaw and had a noncontributory medical history. Extraoral examination revealed a diffuse swelling measuring about $1 \mathrm{~cm} . \mathrm{x}$ 1,5 $\mathrm{cm}$. and it had an oval shape (Figure 1). On palpation the swelling was non-tender and bony hard and it was strongly attached to the body of mandible. Skin overlying the swelling showed adhesion because of the mass due to local irritation and trauma. Intraoral examination revealed a well-defined subperiosteal mass on the buccal plate of the right mandible which extended from the right lower of first molar to the second molar. Overlying mucosa was normal and the lesion was hard to palpate. Additionally, we examined a deep carious lesion in the mandibular right first molar and it had exposed pulp.

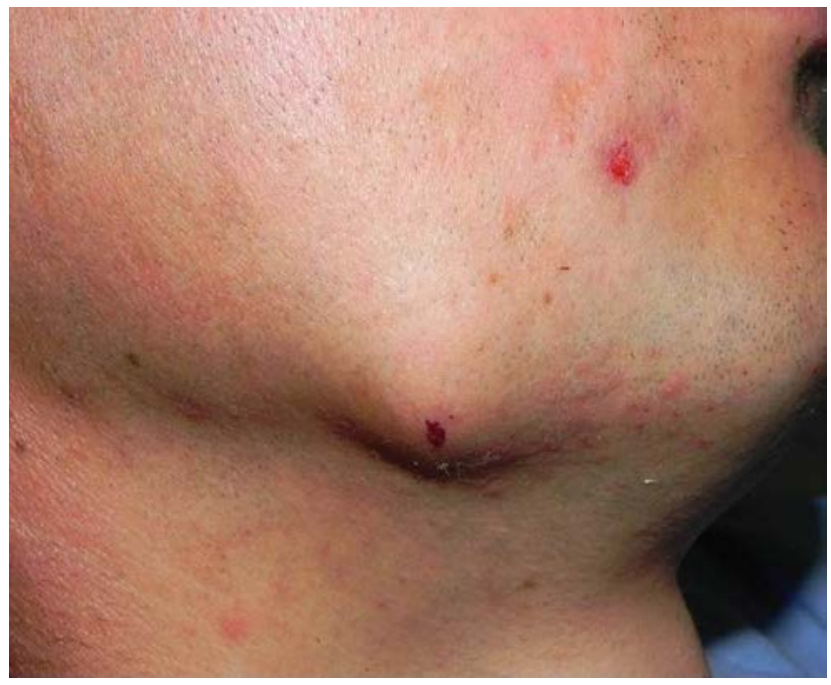

Figure 1. Extraoral photograph shows a swelling on the right mandibular posterior region 
Sagittal and three-dimensional computed tomography scans showed a dense and well- circumscribed radiopaque mass on the inferior border of the right side of the mandible (Figure 2).
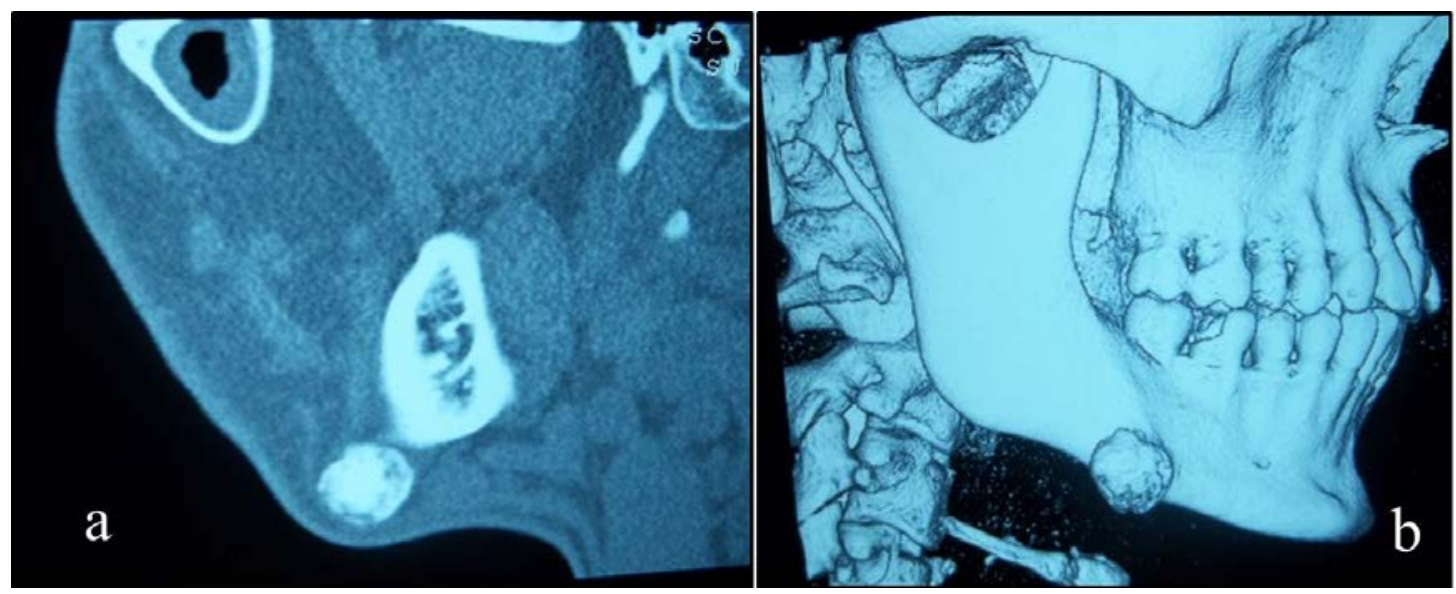

Figure 2. Radiographic appearance of the radiopaque mass on the computed tomography (a. Sagittal section; b. 3D section)

The proposed treatment involved surgical excision with the patient under general anesthesia. A full-thickness buccal mucoperiosteal flap was reflected from the rightside of first premolar to second molar. The mass appeared well circumscribed and attached pedicle to the side of the mandible body. Intraoperatively, the limits between the normal bone and the lesion were unclear, even though the latter was protruding and it was harder than normal bone. After the bone mass was exposured adequately, it was excised with the chisel, mallet and rotary instruments. After the cortical plate of mandibular body was debrided and smoothed the flap was sutured. A part of the protruding lesion was harvested to obtain a definite histological diagnosis (Figure 3). Microscopic examination of the specimen revealed, the tissue structure differed significantly from the normal bone structure such as vital compact and mature medullary bone tissue, showing osteocytes and medullary spaces containing a loose connective tissue with capillaries. Histologically, the diagnosis of peripheral osteoma was confirmed (Figure 4).

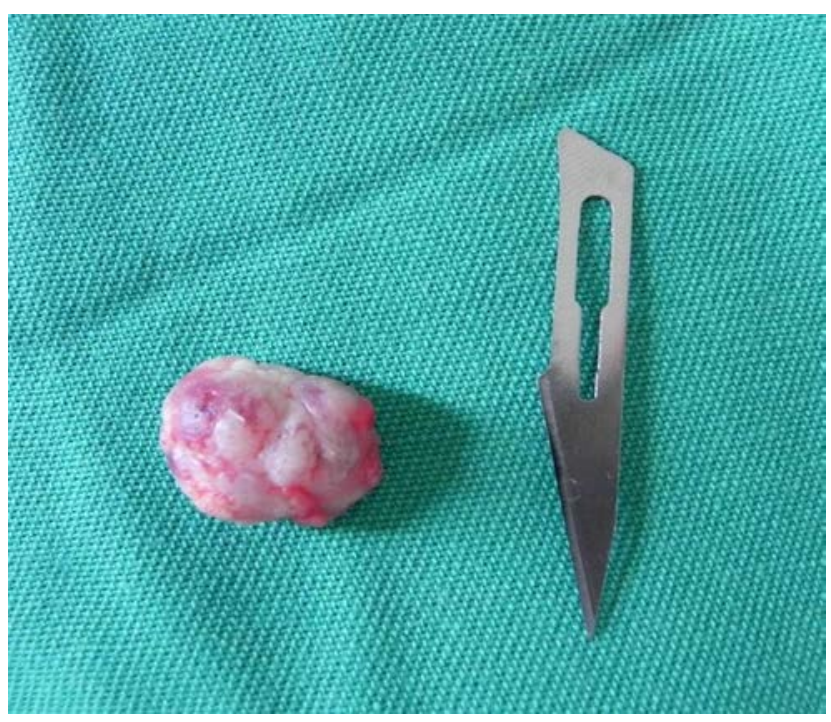

Figure 3. The appearance and size of the mass after surgical excision.

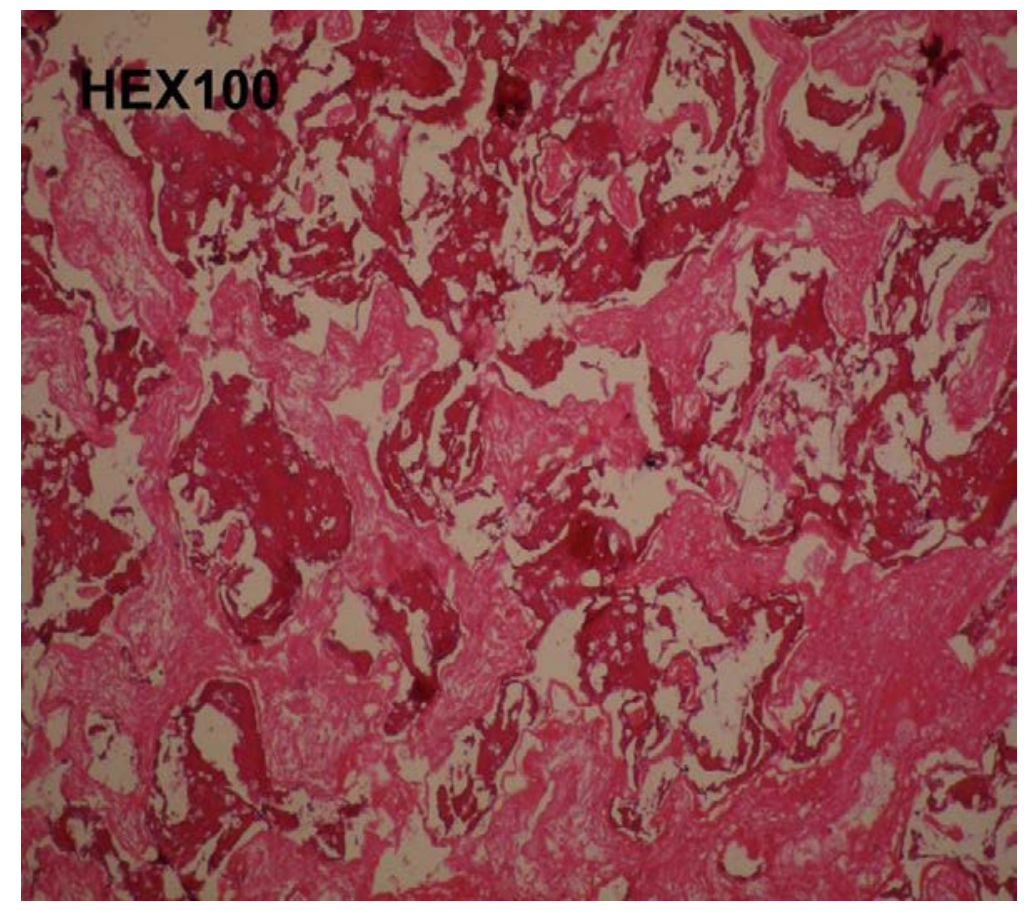

Figure 4. Histopathologic image of the lesion. HEX100 
The patient tolerated the procedure well. Sutures were removed on the seventh day after operation and the postoperative course was uneventful. The patient was scheduled for regular follow up appointments. At the 6month follow-up, the wound healed and it was filled with bone had normal density.

\section{Discussion}

Osteoma is often slow growing but it has continuous growth. It often remains undetected unless incidentally found on a routine clinical and radiographic examination. Osteoma produces symptoms by compression, rather than by invasion or destruction [4]. Sometimes, depending on the location and size of the lesion, it may cause swelling, facial asymmetry, and functional impairment. The swelling is usually painless [1]. In present case, the lesion had reached large dimensions and caused facial asymmetry, without any other clinical symptoms.

The differential diagnosis of peripheral osteoma includes exostoses, osteoblastomas and osteoid osteomas. Exostoses are bony excrescences of reactive or developmental origin that occur on the buccal aspect of alveolar bone. They are not thought to be true neoplasm's [5]. Osteoblastomas and osteoid osteomas are frequently painful and may exhibit a more rapid rate of growth than osteomas [6,7].

Osteoma of the jaw bones is quite rare and the mandible is more commonly affected than the maxilla. In the mandible, the most common regions are the angle and lower border of the body, the regions that are more susceptible to trauma [8]. The precise etiology of peripheral osteoma is unclear. Possibility of a reactive mechanism, caused by trauma or infection has also been suggested. Maxillofacial osteoma associated with cutaneous sebaceous cysts, multiple supernumerary teeth and colorectal polyposis is known as Gardner's syndrome [6]. Our patient did not present any sign of this syndrome.

The complete surgical removal of the osteoma may be indicated to correct the asymmetry or if other problems occur, such as blockage of cavities, compression of nerve terminals or vital tissues, desire of definite histopathological diagnosis. In asymptomatic patients, whose lesion presents sufficiently slow growth or has stopped growing, follow-up is recommendable [9].

The surgical approach should be case specific. For the mandible there are intraoral or extraoral approaches. Intraoral approach is always preferable whenever possible, because it prevents damages to the vital structure. Longo et al. [7] suggested that in larger tumors located posteriorly on the mandible, the extraoral approach was better, since it provided for a better exposure and visibility avoiding damage to the important structures in the region. In the present case located in the lover border of the body, we used the intraoral approach for cosmetic reasons. Recurrence of osteoma after surgical excision is extremely rare. There are no reports of malignant transformation of osteoma in the literature [10].

Peripheral osteoma of the mandible is a very rare condition of unknown etiology. In the presented case, the age, gender and region of the lesion are in agreement with the earlier reports of osteomas. In our patient, there was no history of trauma, but there could be a chance that patient experienced minor trauma which he is not aware of. The lesion in our case is an isolated one and no corroborating syndromal features were found.

\section{References}

[1] Ogbureke KU, Nashed MN, Ayoub AF. Huge peripheral osteoma of the mandible: a case report and review of the literature. Pathol Res Pract 2007; 203:185-8.

[2] Cincik H, Gungor A, Ertugrul E, Cekin E, Dogru S. Peripheral osteoma of the mandible mimicking a parotid mass. Eur Arch Otorhinolaryngol 2007; 264:429-31.

[3] Woldenberg Y, Nash M, Bodner L. Peripheral osteoma of the maxillofacial region. Diagnosis and management: a study of 14 cases. Med Oral Patol Oral Cir Bucal 2005; 1:139-42.

[4] Aghabeigi B, Evans AW, Crean SJ, Hopper C. Simultaneous repair of an orbital floor fracture and removal of an ethmoid osteoma: case report and review of the literature. Int $\mathrm{J}$ Oral Maxillofac Surg 2003; 32:94-6.

[5] Johann AC, de Freitas JB, de Aguiar MC, de Araújo NS, Mesquita RA. Peripheral osteoma of the mandible: case report and review of the literature. J Craniomaxillofac Surg 2005; 33:276-81.

[6] Sayan NB, Ucok C, Karasu HA, Guhan O. Peripheral osteoma of the oral and maxillofacial region: a study of 35 new cases. J Oral Maxillofac Surg 2002; 60:1299-301.

[7] Longo F, Califano L, De Maria G et al. Solitary osteoma of the mandibular ramus: report of a case. J Oral Maxillofac Surg 2001; 59:698-700.

[8] Rodriguez R, Rizzo S, Fiandrino G, Lupi S, Galiotio S. Mandibular traumatic peripheral osteoma: a case report. Oral Surg Oral Med Oral Pathol 2011; 112:44-8.

[9] Richardson PE, Arendt DM, Fidler JE, Webber CM. Radiopaque mass in the submandibular region. J Oral Maxillofac Surg 1999; 57:709-13.

[10] Swanson KS, Guttu RL, Miller ME. Gigantic osteoma of the mandible: report of a case. J Oral Maxillofac Surg 1992; 50:63538. 